\title{
PENGARUH FILLER ABU TANDAN SAWIT TERHADAP KARAKTERISTIK MARSHAL PADA CAMPURAN AC-BC
}

\author{
Winayati \\ Program Studi Teknik Sipil Universitas Lancang Kuning \\ Jalan Yos Sudarso Km. 8 Rumbai Pekanbaru \\ E-mail : winayatimt@gmail.com \\ Fadrizal Lubis \\ Program Studi Teknik Sipil Universitas Lancang Kuning \\ Jalan Yos Sudarso Km. 8 Rumbai Pekanbaru \\ E-mail : fadrizal@unilak.ac.id \\ Virgo Trisep Haris \\ Program Studi Teknik Sipil Universitas Lancang Kuning \\ Jalan Yos Sudarso Km. 8 Rumbai Pekanbaru \\ E-mail : virgotrisepharis@gmail.com
}

\begin{abstract}
Abstrak
Dalam upaya meningkatkan kekuatan struktur perkerasan jalan raya khususnya perkerasan Laston, pemilihan jenis material sebagai filler sangat penting karena filler merupakan bahan pengisi yang sifatnya halus dan dapat mengisi rongga atau pori yang berukuran diameter lebih kecil atau kurang dari $0,002 \mathrm{~mm}$, salah satu limbah yang dihasilkan oleh industri perkebunan kelapa sawit memberikan peluang alternatif material penyusun campuran aspal (filler). Berdasarkan pengujian awal terhadap abu tandan sawit, dari analisis saringan diperoleh hasil bahwa abu tandan sawit $65 \%$ lolos saringan No.200, pada pengujian saringan basah filler abu tandan sawit memenuhi gradasi yang ditentukan. Bahan pengisi pada campuran yang sering digunakan pada proses pembuatan aspal di AMP (Asphalt Mixing Plant) adalah abu batu dan semen portland. Abu tandan sawit merupakan salah satu limbah non plastis, sesuai dengan persyaratan bahan yang bisa digunakan untuk bahan pengisi. Dari rekomendasi penelitian Afrian (2016), campuran AC-BC yang memenuhi Spesifikasi Umum Bina Marga 2010, yakni 25\% filler abu tandan sawit dicampur dengan 75\% Abu Batu dari berat total filler dalam campuran. Variasi tersebut dalam campuran AC-BC memenuhi standar karakteristik Marshall, yaitu stabilitas, flow, VIM, VMA, VFA, MQ, IRS, yang menjadi dasar penelitian selanjutnya dengan melihat pengaruh filler ABS terhadap karakteristik Marshall khususnya nilai rongga dalam campuran (VIM) akibat penambahan persentasi ABS yang dilakukan di laboratorium. Dari hasil analisis regresi linier didapat persamaan $\mathrm{Y}=0.245+0.001 \mathrm{X}$, artinya variabel persentase ABS $(25 \%)$ berpengaruh terhadap nilai VIM, tetapi pengaruhnya sangat kecil, $r^{2}=0,035$ artinya hubungan antara persentasi ABS yang dicampurkan, berpengaruh pada nilai VIM yang terjadi tetapi relatif kecil.
\end{abstract}

Kata Kunci : Abu Kelapa Sawit, Pengaruh, Rongga dalam Campuran 


\begin{abstract}
In an effort to increase the strength of the pavement structure highways especially pavement Laston, the choice of material as filler is very important because the filler is a filler material that is subtle and can fill the cavity or pore diameter less than or less than $0.002 \mathrm{~mm}$, one of the wastes produced by palm oil industry provides alternative opportunities asphalt mixture of constituent materials (filler). Based on early testing on palm bunch ash, sieve analysis of the obtained results that palm bunch ash $65 \%$ through sieve 200, the wet sieve testing of palm bunch ash filler meets the specified gradation. The filler in the mixture that is often used in the production of asphalt in AMP (Asphalt Mixing Plant) is a stone dust and Portland cement. Abu bunches of a palm is one of non-plastic waste, in accordance with the requirements of materials that can be used for filler. Of recommendation Afrian Research (2016), Mixed $A C-B C$ that meets the Highways General Specification 2010, ie 25\% filler ash mixed palm bunches WITH 75\% Abu stone of weight total filler mixture hearts. Variasi in a mixture of AC-BC meets the characteristics standard Marshall, namely stability, flow, VIM, VMA, VFA, MQ, IRS, which became the basis of further studies to see influence on the characteristics of the filler ABS Marshall in particular the value of the voids in the mixture (VIM) from the additional percentage ABS conducted laboratory. From the results of linear regression analysis obtained equation $Y=0.245+0.001 X$, meaning that the variable percentage of ABS (25\%) effect on the value of VIM, but the effect is very small, $r^{2}=0.035$ means that the relationship between the percentage of ABS was mixed, affects the value of VIM happened but relatively small.
\end{abstract}

Keywords : Ash Palm Oil, The Influence, Void in Mix

\section{A. PENDAHULUAN}

Hasil penelitian Afrian (2016), karakteristik Marshal yang didapat dari penggunaan abu tandan sawit sebagai filler nilainya cenderung mengalami peningkatan dan memenuhi Spesifikasi Umum Bina Marga 2010, pada campuran dengan komposisi $25 \%$ filler abu tandan sawit dicampur $75 \%$ Abu Batu dari berat total filler dalam campuran. Variasi tersebut dalam campuran AC-BC memenuhi standar karakteristik Marshall, antara lain yaitu stabilitas, VIM (Void in the Compacted Mixture), MQ (Marshall Quotient), IRS (Index Retained Strength). Berdasarkan rekomendasi ini, diteliti lebih lanjut apakah filler abu tandan kelapa sawit dapat mempengaruhi nilai karakteristik Marshall khususnya VIM (Void in the Compacted Mixture).

\section{B. TINJAUAN PUSTAKA}

\section{Lapis Aspal Beton}

AC-BC adalah salah satu dari tiga macam campuran AC, yaitu AC-BC (Asphalt Concrete - Binder Course), AC-WC (Asphalt Concrete - Wearing Course), AC-Base. Perbedaan ketiga campuran terletak pada perbedaan ukuran bahan agregat yang digunakan sesuai dengan Spesifikasi Umum Bina Marga (Bina Marga, 2010). Penggunaan AC-BC yaitu untuk lapis pondasi atas dalam perkerasan dan mempunyai tekstur yang agak kasar.

\section{Filler}

Bahan pengisi adalah bahan yang lolos ukuran saringan No.30 $(0,59 \mathrm{~mm})$ dan paling sedikit $65 \%$ lolos saringan No.200 (0,075 mm) berdasarkan SNI 036723 (Standar Nasional Indonesia 
Spesifikasi Bahan Pengisi untuk Campuran Beraspal, 2002).

\section{Abu Tandan Sawit (ATS)}

Tandan sawit sebagai sisa pengolahan pabrik kelapa sawit dalam bentuk padat dibakar dan akan menghasilkan Abu Tandan Sawit. Adapun komposisi kimia abu tandan sawit ditunjukkan tabel 1 .

\section{Karakteristik Beton Aspal}

Suatu perkerasan harus memiliki karakteristik tertentu sehingga kuat menahan beban serta aman dan nyaman ketika dilalui kendaraan (Putrowijoyo, 2006) :

a. Stabilitas (Stability), The Asphalt Institute menyatakan bahwa stabilitas adalah kemampuan campuran aspal untuk menahan deformasi akibat beban yang bekerja, tanpa mengalami deformasi permanen seperti gelombang, alur ataupun bleeding dinyatakan dalam satuan $\mathrm{kg}$ atau $\mathrm{lb}$. Nilai stabilitas diperoleh dari hasil pembacaan langsung pada alat Marshall Test sewaktu melakukan pengujian Marshall.

b. Flow, adalah besarnya deformasi vertikal benda uji yang terjadi mulai saat awal pembebanan sampai kondisi kestabilan maksimum sehingga sampel sampai batas runtuh dinyatakan dalam satuan mm.

c. Durabilitas, yaitu kemampuan suatu lapis perkerasan jalan untuk mempertahankan diri dari kerusakan atau mencegah keausan karena pengaruh lalu lintas, pengaruh cuaca dan perubahan suhu yang terjadi selama umur rencana. Faktor yang mempengaruhi durabilitas aspal beton adalah :

1). Selimut aspal yang tebal sehingga dapat menghasilkan perkerasan yang berdurabilitas tinggi, tetapi kemungkinan terjadi bleeding tinggi.

2). VIM (Void In Mix) kecil, sehingga lapis kedap air dan udara tidak masuk ke dalam campuran yang menyebabkan terjadinya oksidasi dan aspal menjadi rapuh.

3). VMA (Void in Material) besar, sehingga selimut aspal dibuat tebal. Jika VMA dan VIM kecil serta kadar aspal tinggi kemungkinan terjadi bleeding besar. Untuk mencapai VMA yang besar ini dipergunakan agregat bergradasi senjang.

Tabel 1. Komposisi Kimia Abu Tandan Sawit (ATS)

\begin{tabular}{lc}
\hline \multicolumn{1}{c}{ Parameter } & Hasil analisis $(\boldsymbol{\%})$ \\
\hline Kalium $(\mathrm{K})$ & 25,8 \\
Silika $(\mathrm{Si})$ & 19,1 \\
Calsium $(\mathrm{Ca})$ & 2,7 \\
Magnesium $(\mathrm{Mg})$ & 2,8 \\
Natrium $(\mathrm{Na})$ & 0,03 \\
Posfat & 0,2 \\
Klor $(\mathrm{Cl})$ & 4,9 \\
$\mathrm{CO} 3$ & 9,2 \\
\hline
\end{tabular}

(Sumber : Zahrina, 2007) 


\section{Analisa Model Regresi Linier Berganda dan Korelasi}

Analisis regresi adalah metode yang mempelajari hubungan fungsional antara variabel-variabel dalam bentuk matematik. Variabel-variabel dalam analisis regresi dibedakan atas dua jenis yaitu variabel bebas (independent) dan variabel tak bebas (dependent).

Dalam kasus penelitian ini, analisis yang digunakan adalah regresi linier berganda karena variabel yang diuji lebih dari satu variabel. Persamaan berikut ini memperlihatkan bentuk umum metode analisis regresi-linearberganda :

$$
\mathrm{Y}=\mathrm{a}+\mathrm{b}_{1} \cdot \mathrm{x}_{1}+\mathrm{b}_{2} \cdot \mathrm{x}_{2}+\ldots .+\mathrm{b}_{\mathrm{n}} \cdot \mathrm{x}_{\mathrm{n}}
$$

\section{Dengan :}

$$
\begin{array}{ll}
\mathrm{Y} & =\text { Peubah tidak bebas } \\
\mathrm{x}_{1} \ldots \mathrm{x}_{\mathrm{n}} & =\text { Peubah bebas } \\
\mathrm{a} & =\text { Konstanta } \\
\mathrm{b}_{1} \ldots \mathrm{b}_{\mathrm{n}} & =\text { Koefisien regresi }
\end{array}
$$

Husaini, U., Akbar R.P.S., (1995), mengemukakan bahwa analisa korelasi adalah suatu teknik analisa statistik yang dipakai untuk menghubungkan dua variabel atau lebih. Hal yang sering digunakan dalam menetapkan seberapa kuat hubungan antara variabel atau untuk menetapkan kecocokan dari suatu model estimasi kurva dipergunakan suatu mutu penjajangan (goodness of fit) yang disebut koefisien korelasi atau r. Jika koefisien korelasi tersebut dikuadratkan, akan didapatkan koefisien determinasi $\left(\mathrm{r}^{2}\right)$, nilai $\mathrm{r}^{2}$ berada pada $0 \leq \mathrm{r}^{2} \leq 1$. Nilai $\mathrm{r}^{2}=1$ menyatakan adanya hubungan linier sempurna dan $r^{2}=0$ menyatakan tidak ada hubungan linier antara variabel $\mathrm{X}$ dengan variabel $\mathrm{Y}$.

Sedangkan untuk mengetahui arah hubungan kedua variabel dilihat dari tanda (+ dan -), tanda (-) pada nilai $r$ akan menunjukan hubungan yang berlawanan arah, sedangkan (+) menunjukan hubungan searah. Untuk lebih lengkapnya interprestasi nilai $r$ dapat ditunjukkan pada tabel 2.

Tabel 2. Interprestasi dari Nilai $r$

\begin{tabular}{cl}
\hline $\mathbf{r}$ & \multicolumn{1}{c}{ Interprestasi } \\
\hline 0 & Tidak berkorelasi \\
$0,01-0,20$ & Sangat rendah \\
$0,21-0,40$ & Rendah \\
$0,41-0,60$ & Agak rendah \\
$0,61-0,80$ & Cukup \\
$0,81-0,99$ & Tinggi \\
1 & Sangat tinggi \\
\hline
\end{tabular}

(Sumber : Husaini, U., Akbar, R.P.S., 1995)

\section{DATA DAN ANALISA DATA}

\section{Lokasi Penelitian}

Penelitian dilakukan di Laboratorium Dinas Pekerjaan Umum Provinsi Riau Bidang Unit Pelaksana Teknis (UPT) Pengujian yang beralamat di Jalan Sudirman No.197 Pekanbaru.
Dengan dasar menggunakan sistem pencampuran aspal panas AC$\mathrm{BC}$ dengan panduan Spesifikasi Umum Bina Marga (2010) yang merupakan dasar dari pembangunan jalan raya. Sedangkan standar-standar pengujian yang digunakan sebagian menggunakan standar dari metode-metode yang 
disahkan atau distandarkan oleh Bina Marga bahkan ada yang telah menjadi Standar Nasional Indonesia (SNI).

Pengujian dalam penelitian ini dilakukan secara bertahap, yaitu terdiri atas pengujian agregat (kasar, halus dan filler), aspal dan pengujian terhadap campuran (uji Marshall).

\section{Metode Analisis Data}

Dalam melakukan penelitian ini dibutuhkan juga bahan dan alat bantu untuk pengolahan data sebagai berikut :

a. Perangkat Lunak (software)

1). Microsoft Excel

Digunakankan sebagai alat bantu untuk menampilkan hasil analisa dari data yang ditampilkan dalam bentuk grafik dan pengkodean data.

2). SPSS (Statistical Product and Servicer Solutions) versi 17

Digunakan sebagai alat bantu untuk menyelesaikan berbagai analisis statistik. Analisa yang dilakukan dengan menggunakan program uji validitas, korelasi bivariat, regresi linier

b. Perangkat Keras (hardware)

Perangkat keras yang digunakan adalah timbangan, alat tulis, hand counter, material.

Sampel perkerasan AC-WC dengan $25 \%$ ATS dan $75 \%$ ATB sebanyak 10 sample digunakan untuk mendapatkan data-data laboratorium, data variabel tidak bebas (independent variable) persentase abu tandan sawit dan data variabel bebas (dependent variabel) nilai VIM 10 benda uji.

\section{HASIL DAN PEMBAHASAN}

Berdasarkan hasil penelitian, diperoleh kadar aspal optimum untuk variasi filler , $25 \%$ abu batu : $75 \%$ abu tandan sawit adalah 5,9\% seperti terlihat pada tabel 3 .

Tabel 3. Kadar Aspal Optimum

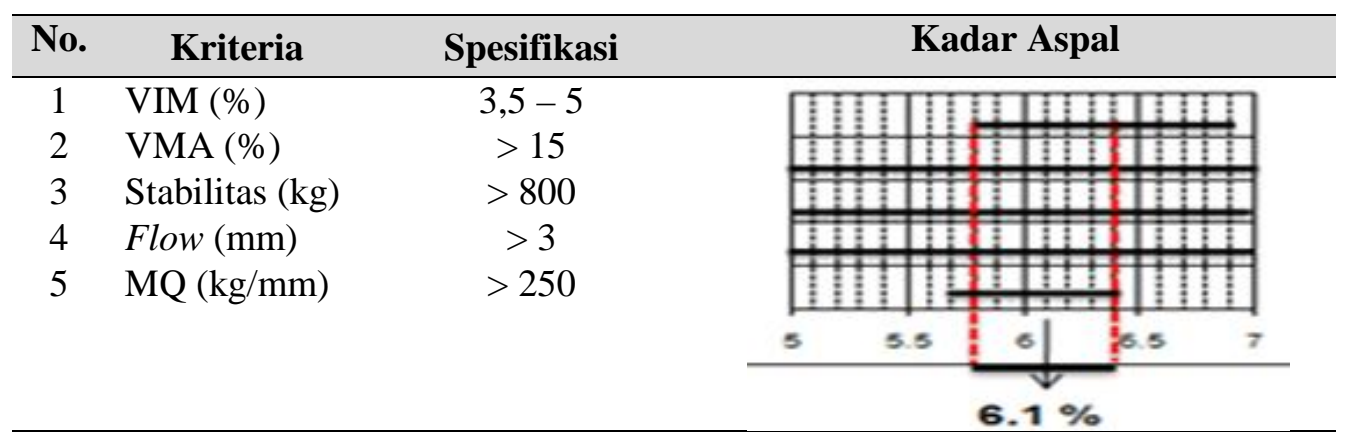

\section{Rongga dalam Campuran (Void in Mix - VIM)}

Rongga dalam campuran (Void in Mix - VIM) merupakan ruang udara yang ada di antara partikel agregat yang telah diselubungi oleh aspal di dalam campuran yang telah dipadatkan dan dinyatakan dalam persen dari volume total. Nilai VIM merupakan ukuran yang umum dikaitkan dengan durabilitas dan kekuatan dari campuran. Nilai VIM yang lebih kecil akan menyebabkan terjadinya bleeding yaitu keluarnya aspal ke permukaan perkerasan AC-BC saat pemadatan oleh beban lalu lintas. Sedangkan nilai VIM yang lebih besar menyebabkan campuran perkerasan ACBC kurang kedap air sehingga mengakibatkan campuran cepat mengalami kerusakan. 
Pertambahan kadar aspal akan menyebabkan semakin kecil nilai VIM, hal ini disebabkan aspal lebih bayak mengisi rongga-rongga dalam campuran sehingga rongga-rongga di dalam campuran perkerasan AC-BC semakin kecil.

Spesifikasi Umum Bina Marga (2010), memberi batasan untuk VIM 3,5 $\mathrm{mm}$ dan maksimum $5 \mathrm{~mm}$. Nilai VIM untuk variasi kadar aspal dengan variasi kadar filler dapat dilihat pada Gambar 1.

Penambahan kadar aspal akan menyebabkan mengecilnya nilai VIM, hal ini dikarenakan penambahan kadar aspal dapat menyebabkan aspal lebih banyak mengisi rongga-rongga dalam campuran. Pada kondisi kadar aspal optimum nilai VIM terbesar terdapat pada campuran dengan variasi filler abu tandan sawit $100 \%$ yaitu $6,23 \%$. Sedangkan untuk nilai VIM terendah terdapat pada campuran dengan variasi filler abu tandan sawit $100 \%$ yaitu $5,77 \%$. Untuk lebih jelasnya nilai stabilitas pada kadar aspal optimum dapat dilihat pada gambar 2 .

Gambar 2 memperlihatkan terjadi peningkatan nilai VIM sebesar 6,23\% dari campuran dengan variasi filler 25\% abu batu. Filler abu tandan sawit menyebabkan VIM semakin kecil karena membutuhkan kadar aspal yang banyak dalam campuran yang menyebabkan lebih banyak aspal yang mengisi ronggarongga di dalam campuran.



Gambar 1. Grafik Hubungan VIM dengan Kadar Aspal

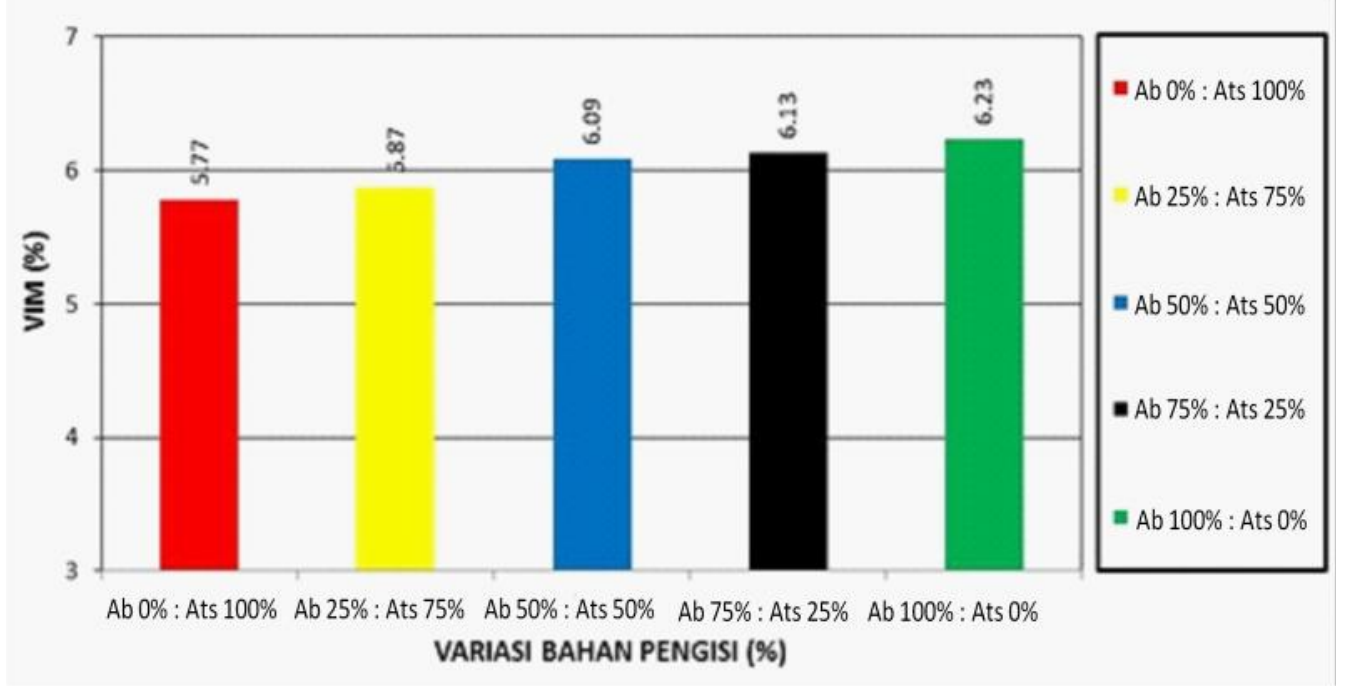

Gambar 2. Hubungan VIM dengan variasi filler pada kondisi KAO 


\section{Hasil Analisis Uji Sampel Laboratorium}

Kinerja campuran AC-BC menggunakan filler abu batu lebih baik dibandingkan campuran AC-BC menggunakan filler abu tandan sawit. Hal ini dikarenakan campuran AC-BC menggunakan filler memiliki stabilitas, VIM, VMA, MQ, dan IRS menunjukkan nilai di atas nilai yang disyaratkan dalam Spesifikasi Umum Bina Marga 2010.

Hasil regresi linier $\mathrm{Y}=0.245+$ $0.001 \mathrm{X}$, artinya variabel persentase ABS berpengaruh uji statistik analisis regresi linier hubungan antara variabel VIM dengan persentase ABS yang dicampurkan, dihasilkan persamaan positif terhadap nilai VIM (Void In Mix), tetapi pengaruhnya sangat kecil, ini dibuktikan dengan hasil uji $\mathrm{r}^{2}=$ 0,035 artinya hubungan antara variabel VIM dengan persentase ABS punya hubungan linier tetapi kurang sempurna.

\section{E. KESIMPULAN}

Dari penelitian campuran AC-BC yang memenuhi Spesifikasi Umum Bina Marga 2010, yakni 25\% filler abu tandan sawit dicampur dengan $75 \%$ Abu Batu dari berat total filler dalam campuran.Variasi tersebut dalam campuran AC-BC memenuhi standar karakteristik Marshall, yaitu stabilitas, flow, VIM, VMA, VFA, MQ, IRS, sehingga pengaruh filler ABS terhadap karakteristik Marshall, dilihat dari nilai rongga dalam campuran (VIM) akibat penambahan persentasi ABS yang dilakukan dilaboratorium menghasilkan suatu nilai tertentu, Dari analisis regresi linier didapat persamaan $\mathrm{Y}=$ $0.245+0.001 \mathrm{X}$, artinya variabel persentase ABS (25\%) yang dipergunakan berpengaruh terhadap nilai VIM, tetapi pengaruhnya sangat kecil, $r^{2}=0,035$ artinya hubungan antara persentasi ABS yang dicampurkan, berpengaruh pada nilai VIM yang terjadi tetapi relatif kecil.

\section{DAFTAR PUSTAKA}

Ahmad M., 2010, Kajian Karakter Indirect Tensile Strength Asphal Concrete Recycle dengan Campuran Aspal Penetrasi 60/70 dan Residu Oli pada Campuran Hangat, Skripsi Teknik Sipil, Universitas Sebelas Maret, Surakarta.

Ditjen Bina Marga, 2010, Spesifikasi Campuran Beraspal Panas pada Spesifikasi Umum Jalan dan Jembatan, Direktorat Jenderal Bina Marga, Jakarta.

Ditjen Bina Marga, 2003, RSNI-M-01. Metode Pengujian Campuran Beraspal Panas dengan Alat Marshall, Pustran Balitbang Pekerjaan Umum, Jakarta.

Ditjen Bina Marga, 2002, SNI-03-6723. Spesifikasi Bahan Pengisi untuk Campuran Beraspal, Pustran Balitbang Pekerjaan Umum, Jakarta.

Ditjen Bina Marga, 1991, SNI-06-6441. Metode Pengujian Kehilangan Berat Minyak dan Aspal dengan Cara A, Pustran Balitbang Pekerjaan Umum, Jakarta.

Fauzi Y., dkk., 2008, Kelapa Sawit, Penebar Swadaya, Jakarta.

Sentosa S., 2006, Penggunaan Abu Gambut Sebagai Filler pada Campuran Lapis Aspal Beton dengan Pengujian Marshall, Jurnal Media Teknik Sipil, Universitas Riau, Pekanbaru.

Badan Standarisasi Nasional, 2008, Cara Uji Berat Jenis dan Penyerapan Air Agregat Kasar, BSN, Jakarta. 
Mutohar Y., 2002, Evaluasi pengaruh Bahan Filler Fly Ash Terhadap Karakteristik Campuran Emulsi Bergradasi Rapat (CEBR), Tesis Magister, Universitas Diponegoro, Semarang.

Putrowijoyo R., 2006, Kajian Laboratorium Sifat Marshall dan Durabilitas Asphalt ConcreteWearing Course (AC-WC) dengan Membandingkan Penggunaan antara Semen Portland dan Batu sebagai Filler, Tesis Magister, Universitas Diponegoro, Semarang.
Sukirman S., 2003, Perkerasan Lentur Jalan Raya, Nova, Bandung.

Sukirman S., 2003, Beton Aspal Campuran Panas, Granit, Jakarta.

Zahrina I., 2007, Pemanfaatan Abu Sawit dan Cangkang Sawit Sebagai Sumber Silika pada Sintesis ZSM-5 dari Zeolit Alam, Jurnal Sains dan Teknologi, Universitas Riau, Pekanbaru. 